\title{
Article \\ Chemical Characterization and Preliminary Evaluation of the Efficacy and Tolerability of a Food Supplement Based on Pomegranate Extract, B Vitamins, and Vitamin C against Prolonged Fatigue in Healthy Consumers
}

\author{
Cristina Esposito ${ }^{1}$, Cristina Santarcangelo ${ }^{1} \mathbb{D}$, Alessandro Di Minno ${ }^{1} \mathbb{D}$, Roberto Sacchi $^{2}$, Eduardo Sommella ${ }^{3}$, \\ Lorenza Francesca De Lellis ${ }^{1}$, Maria Antonietta De Pasquale ${ }^{1}$, Francesca Montarolo ${ }^{1}$, Pietro Campiglia ${ }^{3,4}$ (D), \\ Alessandra Baldi ${ }^{5}$ (D) Costanza Riccioni ${ }^{6}$ and Maria Daglia ${ }^{1,7, *}$
}

check for

updates

Citation: Esposito, C.; Santarcangelo,

C.; Di Minno, A.; Sacchi, R.; Sommella, E.; De Lellis, L.F.; De Pasquale, M.A.; Montarolo, F.; Campiglia, P.; Baldi, A.; et al. Chemical Characterization and Preliminary Evaluation of the Efficacy and Tolerability of a Food Supplement Based on Pomegranate Extract, B Vitamins, and Vitamin C against Prolonged Fatigue in Healthy Consumers. Processes 2022, 10, 208. https://doi.org/10.3390/pr10020208

Academic Editor: Ángeles

Alonso-Moraga

Received: 8 December 2021

Accepted: 18 January 2022

Published: 22 January 2022

Publisher's Note: MDPI stays neutral with regard to jurisdictional claims in published maps and institutional affiliations.

Copyright: (C) 2022 by the authors. Licensee MDPI, Basel, Switzerland. This article is an open access article distributed under the terms and conditions of the Creative Commons Attribution (CC BY) license (https:// creativecommons.org/licenses/by/ $4.0 /)$.
1 Department of Pharmacy, University of Naples Federico II, 80131 Naples, NA, Italy; cristina.esposito@unina.it (C.E.); cristina.santarcangelo@unina.it (C.S.); alessandro.diminno@unina.it (A.D.M.); lo.delellis@studenti.unina.it (L.F.D.L.); depasquale@student.unisi.it (M.A.D.P.); f.montarolo@studenti.unina.it (F.M.)

2 Applied Statistic Unit, Department of Earth and Environmental Sciences, University of Pavia, 27100 Pavia, PV, Italy; roberto.sacchi@unipv.it

3 Department of Pharmacy, University of Salerno, 84084 Fisciano, SA, Italy; esommella@unisa.it (E.S.); pcampiglia@unisa.it (P.C.)

4 European Biomedical Research Institute of Salerno, 84125 Salerno, SA, Italy

5 Tefarco Innova, National Inter-University Consortium of Innovative Pharmaceutical Technologies, 43124 Parma, PR, Italy; alessandra.baldi.alimenti@gmail.com

6 R\&D Department, Esserre Pharma Srl, 00191 Rome, RM, Italy; c.riccioni@esserrepharma.it

7 International Research Center for Food Nutrition and Safety, Jiangsu University, Zhenjiang 212013, China

* Correspondence: mariadaglia@unina.it

\begin{abstract}
Fatigue, characterized by periods of exhaustion that interfere with normal activities and negatively affect quality of life, can be classified as prolonged fatigue (or short-term fatigue, SF) or chronic fatigue. Vitamin deficiency and chronic inflammation seem to be possible causes of fatigue. Due to the unavailability of effective remedies that attenuate fatigue and provide consumer satisfaction, the aim of this investigation is to assess whether a commercial food supplement consisting of pomegranate extract with known anti-inflammatory activity, B vitamins, and vitamin C can help fight SF. To this end, the chemical composition of whole fruit pomegranate dry extract was determined through a RP-UHPLC-HRMS method, which indicated the presence of ellagitannins, gallotannins, and organic and phenolic acids. In a survey of consumers of food supplements aimed at reducing fatigue, 78 subjects ( 21 men and 57 women) were recruited for one month to evaluate the efficacy and tolerability of this food supplement through validated questionnaires for assessing fatigue level and quality of life. The consumers reported a significant improvement in their conditions without adverse effects over this time period. Although further studies are needed, these preliminary data suggest the capacity of a combination of pomegranate extract and hydrosoluble vitamins to alleviate SF.
\end{abstract}

Keywords: pomegranate extract; metabolic profiling; vitamin C; B vitamins; prolonged fatigue; healthy subjects

\section{Introduction}

Fatigue can be defined as a state resulting from physiological and psychological stress that leads to a transient reduction in physical or mental performance (i.e., mental fatigue or physical fatigue) [1]. In general, fatigue is characterized by debilitating periods of exhaustion that interfere with normal activities [2]. The severity and duration of fatigue is variable [3]. Fatigue may result from one or more pathological conditions, but it can also be an entirely physiological condition linked to lifestyle, lack of sleep or bad sleep, stress, 
family and professional concerns, and environmental factors, making it difficult to identify the actual cause [4-6]. One of the most common causes of fatigue is an increase in physical work, leading to a disrupted energy balance due to worked muscle. Muscle fatigue appears quickly and is short-lived. In this case, it has a protective role, warning the subject of the need to rest and recover the body's energy stores. It is traditionally linked to the inhibition of skeletal muscle contraction mechanisms. In fact, the factors involved in fatigue resulting from physical work are numerous and can act at various levels of the chain of command of muscle contraction [7]. In addition to physiological causes, there are also many pathological conditions associated with fatigue, including autonomic dysfunction, malfunctioning of the hypothalamic-pituitary-adrenal axis, and neuroendocrine dysregulation. Moreover, autoimmune diseases (i.e., systemic lupus erythematosus, multiple sclerosis, type 1 diabetes, celiac disease, chronic fatigue syndrome, and rheumatoid arthritis) can cause fatigue [5].

Fatigue can be classified as prolonged fatigue (or short-term fatigue, SF) or chronic fatigue (CFS). SF is a non-pathological condition of fatigue that can be recognized by the subject itself, which consists of persistent or repeated incidence of clinically unexplainable fatigue events. It is an acute form, following physical, mental or infectious triggers, and decreases as triggers recede [3]. The duration of the fatigue period may run from 30 days to six months [1]. CFS, without underlying diseases explaining this symptom, is defined as chronic fatigue syndrome $\backslash$ myalgic encephalomyelitis (CFS $\backslash$ ME). Differently from SF, subjects with CFS are not usually able to restore an adequate energy level, even after a rest or the elimination of the causes. Fatigue can be considered CFS if its duration is longer than six months [8].

Short periods of fatigue occur in $10-33 \%$ of total population. SF is a universal symptom expressed by the majority of the population, occurring in about $5-8 \%$ of the general population, while CFS occurs in 3-4\% of the general population. Fatigue is debilitating and often has significant economic consequences. A Dutch study found that $21.5 \%$ of adult workers reported prolonged fatigue, which may lead to lower productivity at work [4]. There are also affective consequences of fatigue, reported as mood swings and lack of motivation and vitality [6]. Many studies reported that fatigue elicited by physical training translates into worsened sport performance. For instance, cross-country skiers had reduced double poling performance after a 25 min trunk fatiguing exercise sequence, compared with a 25 min rest [9]. Fatigued ballet dancers showed reduced movement control, which may increase the risk of injury [10]. Interestingly, impaired performance appeared to be associated not only with physical and muscular sports, but also with mental factors. For example, table tennis players hit the ball with lower attention and speed after completion of a 90 min cognitive task [11]. In addition, many studies show that in Europe, overtiredness at the wheel is the leading cause of death on the roads and that accidents related to drowsiness are more serious and deadly than those in which sleepiness is not involved [12].

No pharmacological or alternative therapy has been proven effective to date for subjects with CFS [8]. Although some treatments have been tested, such as cognitive behavioral therapies and exercise, both seem to show many limitations. For fatigue caused by pathologies such as multiple sclerosis, modafinil, amantadine, and methylphenidate are used, but according to certain studies these do not have effects much higher than placebo [13].

A detailed review of the literature published in 2000 by Werbach [14] suggests that hydrosoluble vitamins and other macro- and micro-nutrients (i.e., essential fatty acids, Ltryptophan, L-carnitine, coenzyme Q10, magnesium, sodium, and zinc) could be marginally deficient in CFS patients, contributing to the clinical manifestations of the syndrome. More recently, in 2020, Tardy et al. highlighted that vitamins (especially B and C vitamins) are fundamental in most biological processes (i.e., energy metabolism, oxygen transport, and brain functions), concluding that vitamin deficiency can be considered a cause of fatigue [6]. Moreover, growing evidence suggests a link between a pro-inflammatory status and the occurrence of CFS. Haß et al. showed that a balanced diet based on vegetables with high polyphenol or high omega 3 fatty acid content, or based on whole grains rich in fiber, can 
improve disease-related fatigue symptoms [15]. A recent meta-analysis evaluating the data of 16 randomized controlled trials involving 572 subjects on the effect of pomegranate juice on biomarkers of inflammation concluded that pomegranate supplementation exerts a significant effect on hs-CRP, IL- 6 , and TNF- $\alpha$ in adults, confirming the large body of in vitro, in vivo and human evidence that shows the anti-inflammatory activity of pomegranate [16] In addition, recent studies have highlighted that pomegranate improves endurance and performance after physical exercise [17]. In fact, dietary supplementation with pomegranate extracts is recommended for physically active subjects, as it causes improvements in many body functions due to its antioxidant and anti-inflammatory activities [18].

Therefore, assuming that fatigue can be improved through a nutritional intervention [14] aimed at reducing marginal vitamin deficiencies and chronic inflammation, the aim of this investigation is to assess whether a pomegranate extract, $B$ vitamins, and vitamin C-based food supplement can help to fight SF, measured through the administration of questionnaires assessing fatigue level before and after the daily intake of the supplement for one month, and additionally assessing if this food supplement is well tolerated. In addition, the metabolic profile of the whole fruit pomegranate extract used as an ingredient in this food supplement was analyzed using the latest generation of LC-MS instrumentation to deepen knowledge on the chemical composition of the phytocomplex present in this food supplement.

\section{Materials and Methods}

\subsection{Food Supplement}

The food supplement is a commercial product, the distribution of which was notified to the Italian Ministry of Health (notification number: I.5.i.h.2/2021/139191), containing vitamin $C$ (ascorbic acid, $200 \mathrm{mg}$ per 1 stick dose) and the following $B$ vitamins: vitamin $B_{3}$ (niacin, $16 \mathrm{mg}$ per 1 stick dose), vitamin $B_{2}$ (riboflavin, $7 \mathrm{mg}$ per 1 stick dose), vitamin $B_{5}$ (pantothenic acid, $6 \mathrm{mg}$ per 1 stick dose), vitamin $\mathrm{B}_{1}$ (thiamine, $5.5 \mathrm{mg}$ per 1 stick dose), vitamin $B_{6}$ (pyridoxine, $4 \mathrm{mg}$ per 1 stick dose), vitamin $B_{9}$ (folic acid, $200 \mu \mathrm{g}$ per 1 stick dose), vitamin $B_{8}$ (biotin, $50 \mu$ g per 1 stick dose), and vitamin $B_{12}$ (cobalamin, $12.5 \mu \mathrm{g}$ per 1 stick dose); as well as the whole fruit pomegranate dry extract (PunicaPLUS ${ }^{\circledR}$, Rome, Italy, $500 \mathrm{mg}$ per 1 stick dose). As far as PunicaPLUS ${ }^{\circledR}$ composition is concerned, it consists mainly of carbohydrates $(95 \%)$, followed by fat $(1 \%)$, protein $(1 \%)$, and minerals $(3 \%)$, with an energy value of $1711 \mathrm{KJ} / 100 \mathrm{~g}$ ). According to the manufacturer's specifications, this food supplement complies with European specifications for contaminants and microbiological limits.

\subsection{Pomegranate Extract Analysis by UHPLC-HRMS}

An aliquot of pomegranate dry extract $(250 \mathrm{mg})$ was solubilized in methanol/water $(1 \mathrm{~mL}, 30: 70 \mathrm{v} / \mathrm{v})$. The sample was then filtered through a cellulose acetate/cellulose nitrate mixed esters membrane $(0.45 \mu \mathrm{m}$; Millipore Corporation, Billerica, MA, USA) and analyzed by RP-UHPLC-HRMS.

UHPLC-HRMS analysis was performed on a Shimadzu Nexera UHPLC system, coupled online to a hybrid Ion Trap-Time of Flight Mass spectrometer (LCMS-IT-TOF, Shimadzu) equipped with an electrospray source (ESI).

For RP-UHPLC analysis, a Kinetex Biphenyl $100 \mathrm{~mm} \times 2.1 \mathrm{~mm}, 2.6 \mu \mathrm{m}(\mathrm{L} \times \mathrm{I}$.D, particle size, Phenomenex ${ }^{\circledR}$, Bologna, Italy) column was employed with a flow rate of $0.5 \mathrm{~mL} / \mathrm{min}$. The mobile phases consisted of A) $0.1 \% \mathrm{CH}_{3} \mathrm{COOH}$ in $\mathrm{H}_{2} \mathrm{O}$ and $\left.\mathrm{B}\right) \mathrm{CH}_{3} \mathrm{CN}$ plus $0.1 \% \mathrm{CH}_{3} \mathrm{COOH}$. Analysis was performed to a gradient as follows: $0-25 \mathrm{~min}, 2-25 \% \mathrm{~B}$; $25-28 \mathrm{~min}, 25-75 \% \mathrm{~B} ; 28-31 \mathrm{~min}, 75-98 \% \mathrm{~B}$. The column oven was set to $40{ }^{\circ} \mathrm{C}$ and a $2 \mu \mathrm{L}$ sample was injected. PDA detection parameters were sampling rate $12 \mathrm{~Hz}$, time constant $0.160 \mathrm{~s}$, and chromatograms were extracted at 280 and $330 \mathrm{~nm}$. LC data elaboration was performed by LCMS solution ${ }^{\circledR}$ software (Version 3.50.346, Shimadzu).

MS detection was performed in negative ESI ionization as follows: curve desolvation line (CDL), $250{ }^{\circ} \mathrm{C}$; block heater, $250{ }^{\circ} \mathrm{C}$; nebulizing and drying gas, 1.5 and $10 \mathrm{~L} / \mathrm{min}$; 
capillary voltage ESI(-): $-3.5 \mathrm{kV}$; MS range, $m / z$ 150-1500; ion accumulation time, $30 \mathrm{~ms}$; ion trap repeat, 3 . MS/MS was performed in a data dependent acquisition (DDA) mode; precursor ion selection was based on a base peak chromatogram (BPC) intensity of 500.000 . Collision induced dissociation (CID), 50\%, ion trap repeat. For analysis, the instrument was tuned using sodium trifluoroacetate (NaTFA). Metabolite annotation was based on accurate mass measurement, MS/MS fragmentation pattern, and comparison with in silico spectra from MS database searches (mass bank of North America: https:/ / mona.fiehnlab. ucdavis.edu/ and Sirius: https:/ /bio.informatik.uni-jena.de/software/sirius/ accessed on 20 December 2021). "Formula Predictor" software (Shimadzu) was used for the prediction of the molecular formula using the following settings: maximum deviation from mass accuracy: $5 \mathrm{ppm}$, fragment ion information, and nitrogen rule.

\subsection{Evaluation of Efficacy and Tolerability}

\subsubsection{Survey Population}

One hundred and fourteen volunteers aged 18 to 75 with self-reported fatigue who turned to their pharmacist requesting a food supplement for fatigue relief were suggested to try a commercial food supplement based on pomegranate extract, B vitamins, and vitamin $\mathrm{C}$. The initial interview was conducted by the pharmacist. The involved subjects filled out the fatigue questionnaires (Fatigue Assessment Score-FAS, Fatigue Severity Score-FSS, 11-point Numeric Rating Scales-NRS), and the questionnaire on quality of life (Short Form 12 Health Survey-SF-12, subdivided into SF-12 mental and SF-12 physical) in the presence of the physician. The inclusion of the subjects was then evaluated by the physician, who assessed compliance with the inclusion and exclusion criteria. The criteria for inclusion were: the subject must have a sensation of mild to moderate fatigue and feeling of tiredness, the Fatigue Assessment Score (FAS) must be between 22 and 34, and the Fatigue Severity Score (FSS) must be lower than 5. As far as the exclusion criteria are concerned, subjects suffering from chronic diseases or comorbidities potentially explaining the fatigue, malabsorption, anorexia, psychiatric disorders, liver pathologies, heart disease, and kidney pathologies were excluded from this survey. Pregnant and lactating women were also excluded. Subjects with known hypersensitivity to one or more components of the food supplement or subjects using multivitamin supplements in the month before the survey were also excluded. All subjects received oral and written information concerning this survey before they gave their written consent to participate. Any data gathered within this survey was treated in strict accordance with the European Data Protection Regulation (GDPR) and used for research purposes only.

\subsubsection{Survey Design}

A real-life survey was performed to evaluate the effectiveness of a food supplement already present on the market based on pomegranate extract, B vitamins, and vitamin C, in healthy subjects as suggested by the pharmacist, through the evaluation of fatigue (FAS, FSS, and NRS) and quality of life (SF-12 mental and SF-12 physical). The assessment of the tolerability of the food supplement was performed through the evaluation of adverse reactions (ARs) using a form based on that used by the Italian Phytovigilance System (IPS) to report possible ARs after the ingestion of food supplements. Subjects who communicated symptoms related to mild to moderate fatigue to the pharmacist were directed to a separate room, where they received an exhaustive explanation of the survey by a pharmacist. The participants underwent two interviews: at recruitment (i.e., at the baseline, t0) and after 28 days (i.e., after a month of treatment, t1). At recruitment, the inclusion of subjects in the survey was evaluated by the physician, who validated their eligibility and health prior to participation. After they signed written consent, in addition to the self-completion of questionnaires administered by the physician (FAS, FSS and NRS, SF-12 mental and SF-12 physical), each subject was given a form to complete based on that used by the Italian Phytovigilance System (IPS), to report possible ARs after the ingestion of food supplements. These forms were collected at the end of the survey (t1). All subjects took one stick pack 
per day containing $500 \mathrm{mg}$ of pomegranate extract, $200 \mathrm{mg}$ of ascorbic acid, $16 \mathrm{mg}$ of niacin, $7 \mathrm{mg}$ of riboflavin, $6 \mathrm{mg}$ of pantothenic acid, $5.5 \mathrm{mg}$ of thiamine, $4 \mathrm{mg}$ of pyridoxine, $200 \mu \mathrm{g}$ of folic acid, $50 \mu \mathrm{g}$ of biotin, and $12.5 \mu \mathrm{g}$ of cobalamin, for one month.

After they signed the written consent, the first questionnaire submitted to the participants at t0 was the Fatigue Assessment Score (FAS), which is a 10-item questionnaire that explores how the subject usually feels. For each statement, the subjects answers one of the five answers proposed (from "Never" to "Always") [19]. The FAS evaluates overall fatigue. Five questions (1, 2, 4, 5, and 10) reflect physical fatigue and five questions ( 3 and $6-9)$ reflect mental fatigue. The total FAS score was calculated by summing the scores for all questions, with the total score ranging from 10 to 50 . In short, the subjects were divided broadly into two categories based on FAS score: FAS score 10-21: no fatigue (normal), and FAS score 22-50: considerable fatigue. The considerable fatigue group was sub-grouped into mild-moderate fatigue (FAS score: 22-34) or severe fatigue (FAS score: 35-50) [20,21]. Minimal Important Difference (MID) from baseline to the end of the treatment was at least four points or a $10 \%$ change in the patients' FAS score.

The second questionnaire submitted to the participants at t0 was the Fatigue Severity Score (FSS). It is a questionnaire of nine items evaluating both physical and mental fatigue symptoms. Subjects were asked to choose a number from 1 to 7 based on their symptoms (1 indicated absolute disagreement with a statement, while 7 indicated full agreement) [22]. The answer to the questions referred to the previous two weeks. These two scales were chosen because they provided self-completion and are easy to use and manage. In addition, FAS was recently used as a questionnaire for the evaluation of post-COVID-19 fatigue [23], and the FSS scale is the most common scale used, including for healthy subjects [24].

The third questionnaire submitted to the participants at 0 was the 11-point Numeric Rating Scale (NRS). Fatigue NRS is a scale used for the evaluation of fatigue in common clinical practice and clinical trials. It is a self-compilation, single-item, 11 point-horizontal scale from 0 to 10 , where 0 means no fatigue and 10 means severe fatigue [25].

Finally, the fourth questionnaire submitted to the participants at t0 was SF-12. It was used to determine quality of life. The SF-12 questionnaire is a reduced version of the Short Form-36 Health Survey developed in the USA in the 1980s. SF-36 contains 36 questions in which the data are aggregated into eight scales to investigate physical activity, role and physical health, physical pain, general health, vitality, social activities, role and emotional state, and mental health. SF-12 contains only 12 items from the SF-36. It appears to provide a good reproduction of the SF-36 and is in use in many countries. SF-12 is subdivided into evaluations of physical health (PCS) and mental health (MCS), and both have subgroups. For PCS, there are two items on Physical Functioning (PF), two items on Role-Physical (RP), one item about Bodily Pain (BP) and one about General Health (GH). For mental health (MCS), there is an item about Vitality (VT), one item about Social Functioning (SF), two items about Role-Emotional (RE), and two about Mental Health (MH) [26]. To calculate the final score, it is necessary to exclude values out of the range, and four of the items need inverting so that a higher score consistently indicates better health. The indicator variables are weighted using regression coefficients and are standardized by adding a constant (regression intercept) [27].

All the data collected by the physician were categorized into nine sections: the first section included the data of the subject and informed consent (obligatory for all the subjects participating in the proposed survey); the second and third sections concern the inclusion and exclusion criteria of the subjects, respectively; the fourth section summarizes any prior infections contracted within "the last period", and how these (if any) may affect the current survey; in the fifth, sixth, seventh, and eighth sections, FAS, FSS, NRS, and SF-12 scores were calculated for each subject, respectively.

The last section concerns the final evaluation of the subject by the physician based on the data collected.

After 28 days of food supplement intake, the participants were contacted by the physician for the collection of the final data, subdivided into nine sections. The first section 
included the subject data. The second section concerned the compliance of participants. The third section investigated the presence of any adverse effects secondary to the intake of the food supplement (if any). The fourth section investigated the level of satisfaction with the food supplement by the subject. The fifth, sixth, seventh, and eighth sections contained the FAS, FSS, SF-12, and NRS scores, respectively. The last section concerned the final evaluation of the subject by the physician based on the data collected.

\subsubsection{Evaluated Variables}

As far as sociodemographic characteristics are concerned, the age of the participants was considered to be a continuous variable and the gender of the participants a two-levels factor. The primary endpoint was to investigate the efficacy of a one month daily dose of food supplement to reduce mild/moderate fatigue and improve performance. This evaluation was measured at the beginning $(t 0)$ and at the end of the supplement food intake (t1) by the validated questionnaires FAS and FSS. The secondary outcomes considered were the assessment of the quality of life of the subjects through the administration of the quality-of-life questionnaire SF-12 at the baseline and at the end of the food supplement intake, NRS, and tolerability measured as the occurrence of AEs.

Therefore, the endpoints expected were the following: less perception of fatigue and improved quality of life after one month of food supplement intake, without any AEs.

\subsection{Statistical Analysis}

The sample size calculation was made using a $1-\beta$ power value of 0.95 and a significance level $\alpha=0.05$. The sample size was determined to be 84 participants, allowing for a $10 \%$ drop out rate. The objective of the statistical analysis was to compare the score values for the FAS, FSS, NRS, and SF-12 (in the two physical and mental components) scales, measured at the beginning and at the end of the intake of the food supplement, and the characteristics of the subjects recruited (sex and age). The most suitable statistical analysis for this type of data is a linear mixed model with random intercept (LMM) in which the score value of the scales is the dependent variable, while the measurements ( $\mathrm{t} 0$ and $\mathrm{t} 1$ ), sex, and age of the recruited subjects constitute the independent variables. The interaction sex $x$ measurement was been inserted to account for differential responses to measurements between men and women. The identity of the subjects was entered into the model as a random effect to control any differences due to the specific conditions of the persons recruited in the experiment.

\section{Results}

\subsection{Pomegranate Extract Chromatographic Analysis}

RP-UHPLC-UV-HRMS analysis of the whole fruit pomegranate dry extract (PunicaPLUS ${ }^{\circledR}$ ) indicated the presence of 19 main compounds (Figure 1) belonging to different classes such as ellagitannins, gallotannins, phenolic acids, and flavonol glycosides (Table 1). Among ellagitannins, Peak 6 with molecular formula $\mathrm{C}_{34} \mathrm{H}_{22} \mathrm{O}_{22}$ and fragments at $600 \mathrm{~m} / z$ deriving from loss of gallagic acid was assigned as punicalin. Peaks 9 and 15 with molecular formula $\mathrm{C}_{34} \mathrm{H}_{24} \mathrm{O}_{22}$ and precursor ions at $783 \mathrm{~m} / z$ showed fragments at $m / z 765$ and $481 \mathrm{~m} / z$ deriving from the loss of water and hexahydroxydiphenic acid, respectively, leading to their tentative identification as pedunculagin. Peaks 10-12, 13 were detected as doubly charged ions with molecular formula $\mathrm{C}_{48} \mathrm{H}_{28} \mathrm{O}_{30}$ and fragments at $301 \mathrm{~m} / \mathrm{z}$ and $601 \mathrm{~m} / z$ deriving from ellagic acid and gallagic acid losses. For ellagic acid and its glycosilated derivatives, Peaks 16-18, were all characterized by the fragment at $301 \mathrm{~m} / \mathrm{z}$. Gallic acid (Peak 3) derivatives, Peaks 3-5, were characterized by the fragments at 169 $\mathrm{m} / \mathrm{z}$ of gallic acid, deriving from hexose moiety cleavage. Peak 19, with the molecular formula $\mathrm{C}_{20} \mathrm{H}_{16} \mathrm{O}_{12}$, showed a main fragment at $285 \mathrm{~m} / z$ deriving from hexose loss and was assigned as kaempferol hexoside. Peaks 7 and 14 were characterized by fragments at 463, 301 and 169, deriving respectively from the losses of ellagic acid-hexose, ellagic acid, and gallic acid, and were tentatively assigned as HHDP galloyl hexose, while Peak 11, with 
molecular formula $\mathrm{C}_{27} \mathrm{H}_{22} \mathrm{O}_{19}$ and similar fragmentation, was hypothesized as a galloylHHDP-gluconate derivate. Ellagitannins, including two different derivatives of galloyl $(7.96 \%)$, hexahydroxydiphenoyl (HHDP) $(12.28 \%)$, and punicalgin isomers $(66 \%)$ were the most abundant compounds, followed by small amounts of organic acids, represented by citric (1.2\%) and glycosylated flavonoids (1\%) (Table S1).

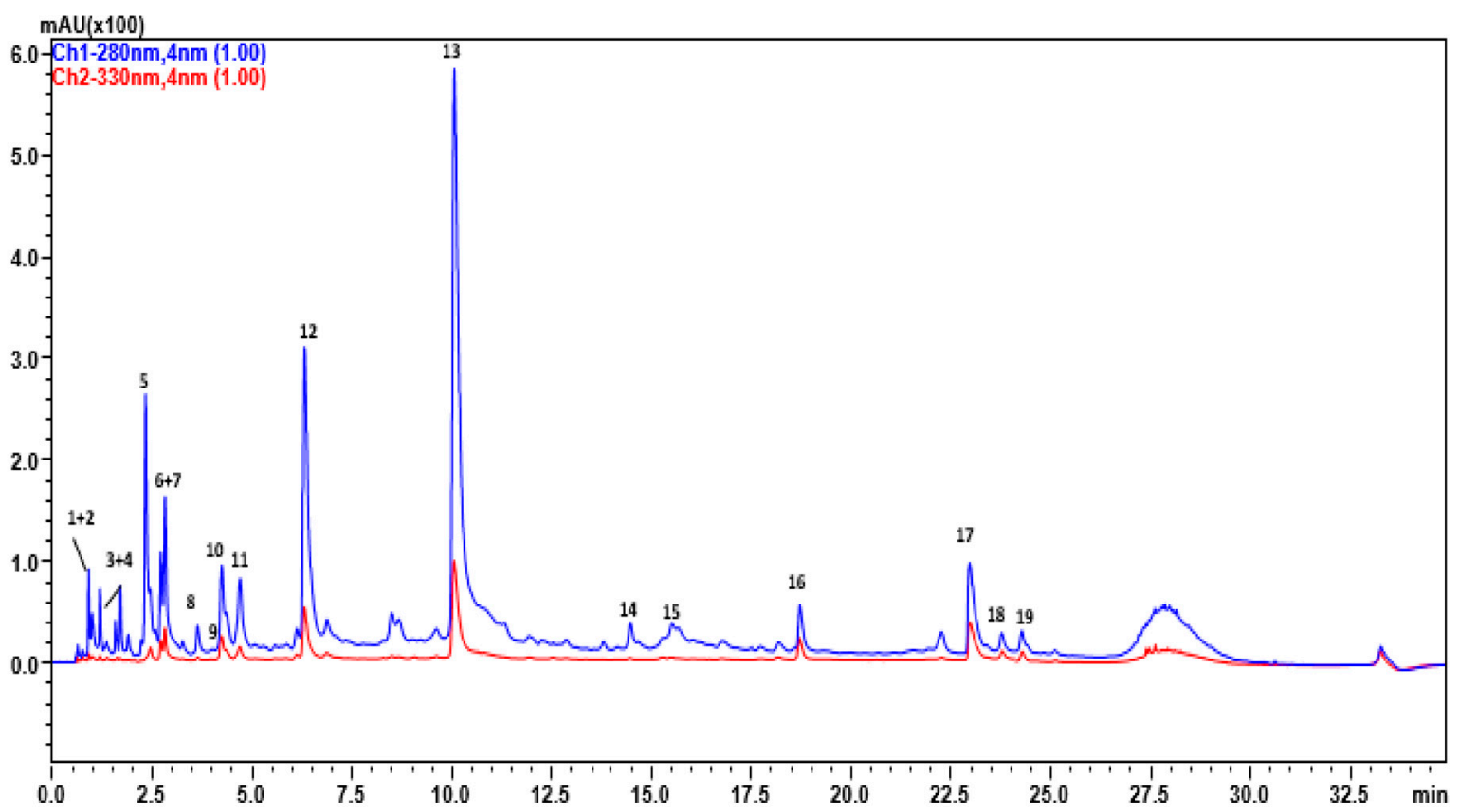

Figure 1. RP-UHPLC-UV-HRMS analysis of pomegranate dry extract (PunicaPLUS ${ }^{\circledR}$ ).

Table 1. Compounds identified in pomegranate dry extract (PunicaPLUS ${ }^{\circledR}$ ) according to their retention time (RT), compound, molecular formula, $m / z$ and MS-MS, and mass accuracy $(\Delta \mathrm{ppm})$, reported as part per million error.

\begin{tabular}{|c|c|c|c|c|c|c|}
\hline Peak & $\operatorname{Tr}$ & Compound & Mol.formula & {$[\mathrm{M}-\mathrm{H}]-/[\mathrm{M}-2 \mathrm{H}] 2^{-}$} & [MS/MS] & Error (ppm) \\
\hline 1 & 1,25 & HHDP-hexose & $\mathrm{C}_{20} \mathrm{H}_{18} \mathrm{O}_{14}$ & 481.0693 & 300,275 & 6.9 \\
\hline 2 & 1,51 & Citric acid & $\mathrm{C}_{6} \mathrm{H}_{8} \mathrm{O}_{7}$ & 191.0194 & 111,173 & 0.85 \\
\hline 3 & 1,6 & Galloyl-hexoside & $\mathrm{C}_{13} \mathrm{H}_{15} \mathrm{O}_{10}$ & 331.0577 & 211,169 & 1.54 \\
\hline 4 & 1,74 & Gallic acid & $\mathrm{C}_{7} \mathrm{H}_{6} \mathrm{O}_{5}$ & 169.0158 & 125,107 & 0 \\
\hline 5 & 2,6 & Galloyl-hexoside \# & $\mathrm{C}_{13} \mathrm{H}_{15} \mathrm{O}_{10}$ & 331.0577 & 211,169 & 1.54 \\
\hline 6 & 2,85 & Punicalin $\beta$ & $\mathrm{C}_{34} \mathrm{H}_{22} \mathrm{O}_{22}$ & 781.0593 & $\begin{array}{c}721,601,575,392,298 \\
273,\end{array}$ & 0 \\
\hline 7 & 3,3 & HHDP galloyl hexose & $\mathrm{C}_{27} \mathrm{H}_{22} \mathrm{O}_{18}$ & 633.0867 & $\begin{array}{c}463,300,275,249,169 \\
125\end{array}$ & -1.3 \\
\hline 8 & 3,67 & Citric acid derivative & $\mathrm{C}_{17} \mathrm{H}_{12} \mathrm{O}_{11}$ & 391.0268 & 270 & -4.35 \\
\hline 9 & 4,03 & Pedunculagin (di-HHDP-hexose) & $\mathrm{C}_{34} \mathrm{H}_{24} \mathrm{O}_{22}$ & 783.0629 & $481,300275,249$ & 0 \\
\hline 10 & 4,29 & Punicalagin * & $\mathrm{C}_{48} \mathrm{H}_{28} \mathrm{O}_{30}$ & $541.0266 *$ & $301,601,275$ & -0.27 \\
\hline 11 & 4,76 & Galloyl-HHDP-gluconate & $\mathrm{C}_{27} \mathrm{H}_{22} \mathrm{O}_{19}$ & 649.0617 & $301,497,626$ & -1.3 \\
\hline 12 & 6,35 & Punicalagin *\# & $\mathrm{C}_{48} \mathrm{H}_{28} \mathrm{O}_{30}$ & 541.0266 & $301,601,275$ & -0.27 \\
\hline 13 & 10,08 & Punicalagin *\# & $\mathrm{C}_{48} \mathrm{H}_{28} \mathrm{O}_{30}$ & 541.0266 & $301,601,275$ & -0.27 \\
\hline 14 & 14,49 & HHDP galloyl hexose \# & $\mathrm{C}_{27} \mathrm{H}_{22} \mathrm{O}_{18}$ & 633.0867 & $\begin{array}{c}463,300,275,249,169, \\
125\end{array}$ & -1.3 \\
\hline 15 & 15,54 & Pedunculagin (di-HHDP-hexose) \# & $\mathrm{C}_{34} \mathrm{H}_{24} \mathrm{O}_{22}$ & 783.0629 & $481,300275,249$ & 0 \\
\hline 16 & 18,73 & Ellagic acid-hexoside & $\mathrm{C}_{26} \mathrm{H}_{32} \mathrm{O}_{13}$ & 551.1749 & $301,389,341$ & -4.92 \\
\hline 17 & 23 & Ellagic acid & $\mathrm{C}_{14} \mathrm{H}_{6} \mathrm{O}_{8}$ & 301.0029 & $229,284,267$ & -4.35 \\
\hline 18 & 23,81 & Ellagic acid-pentoside & $\mathrm{C}_{19} \mathrm{H}_{14} \mathrm{O}_{12}$ & 433.0413 & 301 & 0 \\
\hline 19 & 24,26 & Kaempferol hexoside & $\mathrm{C}_{20} \mathrm{H}_{16} \mathrm{O}_{12}$ & 447.0167 & 285,255 & 5.3 \\
\hline
\end{tabular}

3.2. Survey among Consumers on the Evaluation of Efficacy and Tolerability of the Food Supplement

The survey flow chart is reported in Figure 2. 


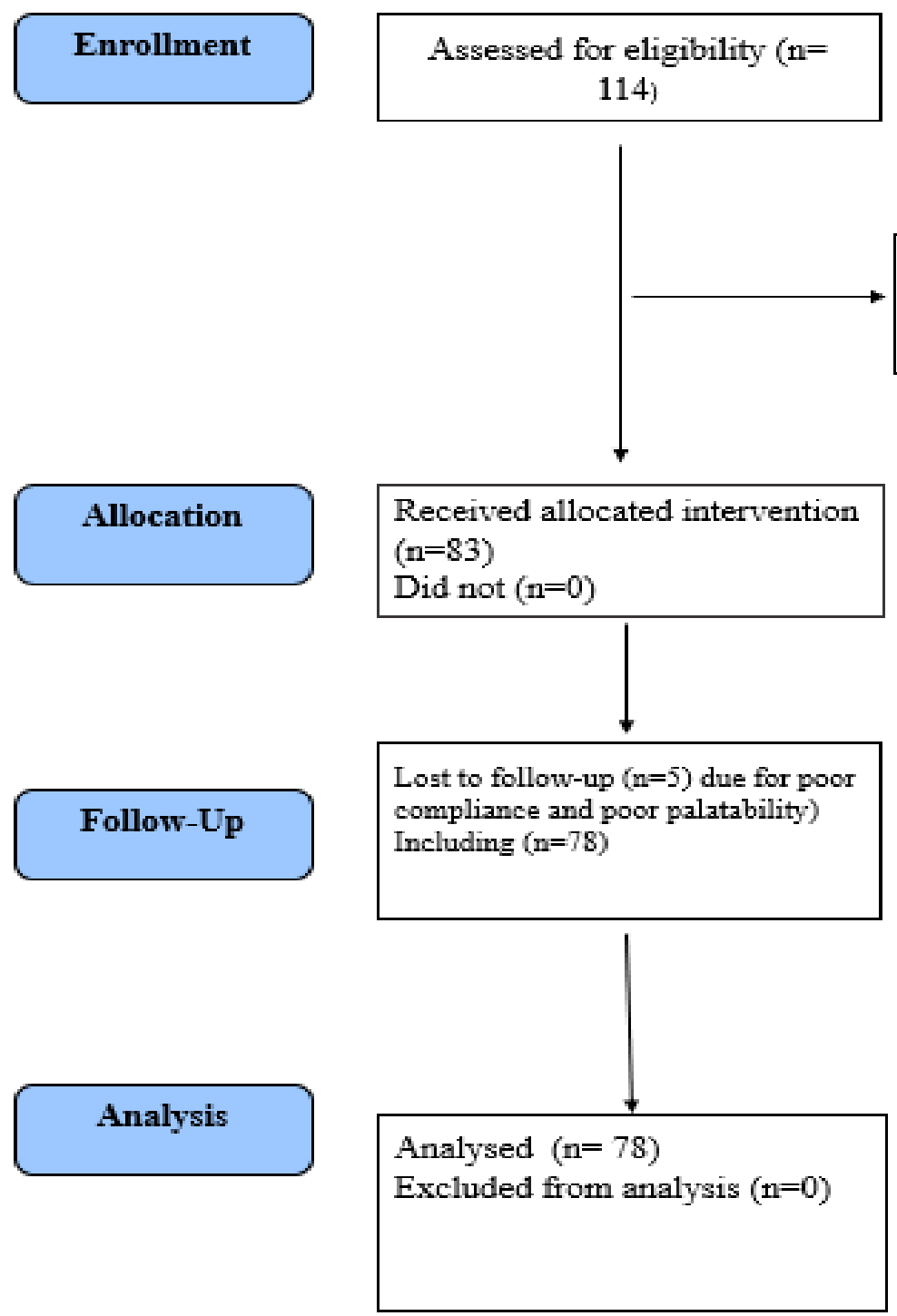

Included ( $\mathrm{n}=83$ )

Not meeting inclusion

criteria $(n=23)$

Figure 2. Flow diagram of the survey among consumers of the food supplement aimed at relieving fatigue.

The participants had similar sociodemographic characteristics, with no significant difference from each other (Table 2).

Table 2. Demographic characteristics of the recruited subjects.

\begin{tabular}{cc}
\hline Demographic Characteristics & \\
\hline Man & 21 \\
Woman & 57 \\
Age in Men & $42.5 \pm 14.5$ \\
Age in Women & $39.8 \pm 13.8$ \\
\hline
\end{tabular}

In Table 3, the descriptive values (mean, standard deviation, and range of values) are given for the score of each assessment scale measured in men and women at $\mathrm{t} 0$ and $\mathrm{t} 1$. 
Table 3. Observed values (mean, standard deviation, minimum and maximum) for fatigue (FAS, FSS, and NRS scales) and quality of life (SF-12) observed in the involved subjects at the beginning ( $\mathrm{t} 0$ ) and at the end (t1) of the food supplement intake.

\begin{tabular}{|c|c|c|c|c|}
\hline \multirow{2}{*}{ Scale } & \multicolumn{2}{|c|}{ Woman } & \multicolumn{2}{|c|}{ Man } \\
\hline & to & t1 & to & t1 \\
\hline FAS & $\begin{array}{c}25.2 \pm 3.7 \\
(10-33)\end{array}$ & $\begin{array}{c}17.8 \pm 4.5 \\
(11-29)\end{array}$ & $\begin{array}{c}24.1 \pm 2.2 \\
(22-30)\end{array}$ & $\begin{array}{c}16.2 \pm 4.4 \\
\quad(9-24)\end{array}$ \\
\hline FSS & $\begin{array}{c}3.2 \pm 1 \\
(1.2-4.8)\end{array}$ & $\begin{array}{l}2.4 \pm 0.7 \\
(1.2-4.6)\end{array}$ & $\begin{array}{l}3.3 \pm 1.0 \\
(1.6-4.9)\end{array}$ & $\begin{array}{c}2.1 \pm 0.7 \\
(1-3.8)\end{array}$ \\
\hline NRS & $\begin{array}{c}5.6 \pm 1.8 \\
(1-10)\end{array}$ & $\begin{array}{c}3.9 \pm 1.8 \\
(1-8)\end{array}$ & $\begin{array}{c}5.0 \pm 1.5 \\
(2-8)\end{array}$ & $\begin{array}{c}3.0 \pm 1.2 \\
(2-6)\end{array}$ \\
\hline SF12-physical & $\begin{array}{l}54.9 \pm 5.8 \\
(35.8-65.8)\end{array}$ & $\begin{array}{l}56.0 \pm 4.3 \\
(41.2-69.2)\end{array}$ & $\begin{array}{c}51.6 \pm 8.3 \\
(36-64.6)\end{array}$ & $\begin{array}{c}54.9 \pm 2.9 \\
(48.5-61.5)\end{array}$ \\
\hline SF12-mental & $\begin{array}{l}41.9 \pm 10.6 \\
(15.7-58.8)\end{array}$ & $\begin{array}{c}51.1 \pm 8.1 \\
(19-64.8)\end{array}$ & $\begin{array}{c}38.8 \pm 11.2 \\
(19-58.7)\end{array}$ & $\begin{array}{c}50.7 \pm 6.2 \\
(35.3-58.7)\end{array}$ \\
\hline
\end{tabular}

\subsection{Primary Outcomes: FAS, FSS, and NRST}

The LMM model (Table 4) identified a statistically significant effect for measurements and an effect near to the significance threshold for sex, while no significant effects were identified for age or the interaction between measurements and sex. In detail, the value of the FAS score decreased between $\mathrm{t} 0$ and $\mathrm{t} 1$ (Figure 3 ) in both men $(-7.9 \pm 1.2$, $\mathrm{t} 76=6.665, p=0.001)$, and women $(-7.4 \pm 0.7, \mathrm{t} 76=10.322, p=0.001)$. Men seemed to have lower values than women $(\mathrm{t} 0:-1.04 \pm 1.01, \mathrm{t} 150=1.027, p=0.30 ; \mathrm{t} 1:-1.51 \pm 1.01$, $\mathrm{t} 150=1.492, p=0.13)$. The random effect between the subjects was not statistically significant $\left(\mathrm{LR} \chi^{2}=0.351, p=0.55\right)$.

Table 4. Results of LMM models for FAS, FSS, and NRS fatigue scales and quality of life (physical and mental SF-12).

\begin{tabular}{|c|c|c|c|}
\hline Model & $\mathbf{F}$ & gdl & $p$ \\
\hline FAS & & & \\
\hline Measurement & 122.17 & 1.76 & $<0.001$ \\
\hline Sex & 2.960 & 1.75 & 0.089 \\
\hline Age & 1.433 & 1.75 & 0.230 \\
\hline $\begin{array}{c}\text { Measurement } \times \text { sex } \\
\text { FSS }\end{array}$ & 0.117 & 1.76 & 0.730 \\
\hline Measurement & 85.694 & 1.76 & $<0.001$ \\
\hline Sex & 0.134 & 1.75 & 0.710 \\
\hline Age & 1.881 & 1.75 & 0.170 \\
\hline $\begin{array}{c}\text { Measurement } \times \text { sex } \\
\text { NRS }\end{array}$ & 1.507 & 1.76 & 0.220 \\
\hline Measurement & 39.239 & 1.76 & $<0.001$ \\
\hline Sex & 6.119 & 1.75 & 0.016 \\
\hline Age & 0.331 & 1.75 & 0.570 \\
\hline $\begin{array}{l}\text { Measurement } \times \text { sex } \\
\text { SF12-physical } \\
\text { component }\end{array}$ & 0.195 & 1.76 & 0.660 \\
\hline Measurement & 5.909 & 1.76 & 0.017 \\
\hline Sex & 4.361 & 1.75 & 0.040 \\
\hline Age & 0.029 & 1.75 & 0.860 \\
\hline $\begin{array}{l}\text { Measurement } \times \text { sex } \\
\text { SF12-mental } \\
\text { component }\end{array}$ & 1.323 & 1.76 & 0.250 \\
\hline Measurement & 39.029 & 1.76 & $<0.001$ \\
\hline Sex & 0.961 & 1.75 & 0.340 \\
\hline Age & 0.188 & 1.75 & 0.670 \\
\hline Measurement $\times$ sex & 0.620 & 1.76 & 0.430 \\
\hline
\end{tabular}



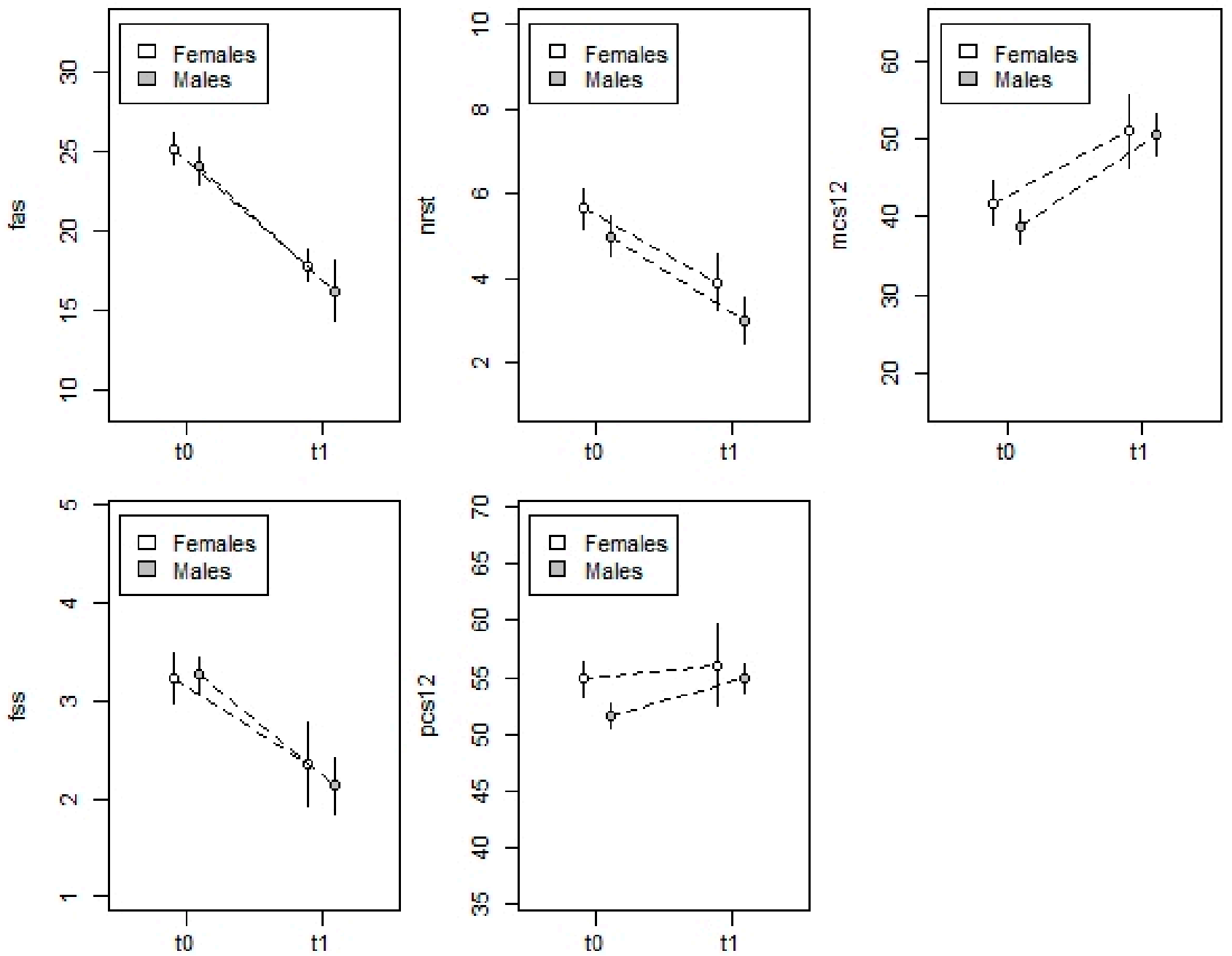

Figure 3. Variation in the intensity (average and 95\% confidence intervals) of the fatigue (FAS, FSS, and NRST scores) and quality of the life (SF12 in the physical component PCS12 and mental component MCS12) observed in the subjects recruited, at the beginning ( $\mathrm{t} 0)$ and at the end (t) of the intake of the pomegranate extract, B vitamins, and vitamin C- based food supplement.

The LMM model for the FSS scale (Table 4) provided results similar and consistent to those observed in the previous analysis for the FAS scale. The only statistically significant effect was the measurement effect, while no significant effects emerged for sex, age, and the sex $\times$ measurement interaction. In detail, the FSS score significantly decreased from t0 to $\mathrm{t} 1$ (Figure 3 ) in both men $(-0.87 \pm 0.11$, t76 = 7.737, $p=0.001)$ and women $(-1.14 \pm 0.18, \mathrm{t} 76=6.132, p=0.001)$. The random effect of the subject was statistically significant $\left(\mathrm{LR} \chi^{2}=22.075, p=0.001\right)$, suggesting that a portion of the variability in the FSS score was due to subject variability not related to sex, age, and experimental measurements.

The LMM model (Table 4) for the NRS scale identified a statistically significant effect for both measurement and sex, while no significant effect was identified for age or for the interaction between measurement and sex. In detail, the NRS score significantly decreased between $\mathrm{t} 0$ and $\mathrm{t} 1$ (Figure 3 ) with a similar pattern in women $(-1.73 \pm 0.31, \mathrm{t} 76=5.611$, $p=0.001)$ and men $(-2.00 \pm 0.51, \mathrm{t} 76=3.922, p=0.001)$. Furthermore, here too, men showed lower NRS scores than women; though the difference was not statistically significant at measurement $\mathrm{t} 0(-0.67 \pm 0.43, \mathrm{t} 150=1.515, p=0.13)$, it was significant at measurement $\mathrm{t} 1(-0.93 \pm 0.44, \mathrm{t} 150=2.115, p=0.036)$. The random effect between the subjects was not statistically significant $\left(\mathrm{LR}^{2}=0.753, p=0.53\right)$. 


\subsection{Secondary Endpoint: SF-12 Physical and SF-12 Mental}

The LMM model (Table 4) for the physical component of the SF-12 scale identified a statistically significant effect for both measurement and sex, while no significant effect emerged for age or the interaction between measurement and sex. In detail, the value of the SF-12 physical index increased from measurement t 0 to measurement $\mathrm{t} 1$, but the response was significant only for men $(+3.34 \pm 1.59, \mathrm{t} 76=2.095, p=0.039$, Figure 3$)$, while for women the variation was not significant $(+1.19 \pm 0.97, \mathrm{t} 76=1.234, p=0.22$, Figure 3$)$. Women showed higher values than men, although the difference was statistically significant only at measurement $\mathrm{t} 0(\mathrm{t} 0:+3.23 \pm 1.39, \mathrm{t} 150=2.321, p=0.022, \mathrm{t} 1:+1.08 \pm 1.39, \mathrm{t} 150=0.781$, $p=0.44$; Figure 3). Finally, the random effect between the subjects was not statistically significant $\left(\mathrm{LR} \chi^{2}=0.753, p=0.39\right)$.

The LMM model (Table 4) for the mental component of the SF-12 scale identified a statistically significant effect for measurements only, while no significant effects emerged for sex, age, or the interaction between measurement and sex. In detail, the value of the SF-12 mental index significantly increased from t0 to t1 (Figure 3$)$ in both women $(+9.22 \pm 1.75$, $\mathrm{t} 151=5.261, p=0.001)$ and men $(+11.88 \pm 2.89, \mathrm{t} 151=17.588, p=0.001$, Figure 3$)$. As in the previous analysis, the random effect was not statistically significant $\left(\operatorname{LR} \chi^{2}=0.001, p=0.99\right)$.

\subsection{Tolerance and Safety Assessment}

For the evaluation of tolerance of the pomegranate extract, B vitamins, and vitamin C-based food supplement, adverse events were monitored throughout the whole period through spontaneous reporting of adverse events (AEs) by the participants to the physician. During the one month of food supplement intake, no subjects reported adverse effects (AEs) related to this food supplement and the physician judged that the food supplement was considered well tolerated.

\section{Discussion}

Vitamin deficiency and chronic inflammation seem to be possible causes of fatigue, and growing evidence suggests that fatigue can be improved through nutritional intervention [14] aimed at reducing marginal vitamin deficiencies and chronic inflammation. Thus, we investigated whether a commercial food supplement consisting of pomegranate extract, which shows anti-inflammatory activity, B vitamins, and vitamin C can help fight SF.

The dry extract from the whole fruit of pomegranate, obtained through a hydroalcoholic extraction and used as an ingredient for a food supplement in a hydrosoluble powder dosage form, was analyzed through a chromatographic method coupled with a hybrid Ion Trap-Time of Flight Mass spectrometer. The extract mainly consists of polyphenols and organic acids. The four main polyphenolic families are ellagitannins (punicalagin, ellagic acid hexose, ellagic acid-pentoside, punicalagin di HHDP hexose, punicalin $\beta$ ), gallotannins (HHDP-hexose, galloyl-hexoside, galloyl-HHDP-gluconate, HHDP galloyl hexose), phenolic acids (ellagic acid and gallic acid), and flavonol glycosides (kaempferol hexoside). The identified compounds are in line with literature data, as pomegranate extract is rich in polyphenolic compounds, flavonoids, and phenolic acids, as well as tannins, which are mainly represented by ellagitannins. In agreement with literature data, the main ellagitannins found in the analyzed pomegranate extract were punicalagin and punicalin, which are the prominent polyphenols isolated from pomegranate fruit [28]. Moreover, citric acid is the most represented organic acid in the pomegranate extract.

After the chemical characterization of the pomegranate extract, a survey among consumers of dietary supplements aimed at alleviating fatigue was conducted to obtain preliminary results on the efficacy on prolonged fatigue and tolerability of a food supplement based on a combination of the chemically characterized pomegranate extract, $\mathrm{B}$ vitamins, and vitamin $C$ in healthy consumers for an intake period of one month.

The method used to perform this survey consisted of: (1) power analysis calculation, to determine the number of subjects involved in the survey; (2) definition of inclusion and exclusion criteria, to accomplish the purpose of the survey; (3) the use of fatigue and quality 
of life questionnaires validated in the general population available in the Italian language; and (4) the use of inferential statistics to analyze the obtained results.

The results of the survey clearly show that the daily intake of the food supplement based on pomegranate extract, B vitamins (at doses ranging from 50 to $500 \%$ of the daily reference intake for vitamins in adults), and vitamin C (at a dose of $250 \%$ of the daily reference intake for vitamin C) for a period of one month may yield a significant improvement in fatigue and quality of life. In fact, after supplementation, FAS, FSS, and NRT scores significantly decreased between $\mathrm{t} 0$ and $\mathrm{t} 1$, and quality of life was consequently improved, as both SF-12 scores (in the physical and mental components) significantly increased. In addition, the food supplement was considered well tolerated by the physician, as no subjects reported adverse effects (AEs) related to consumption of this food supplement.

While it is well known that vitamins, especially B vitamins, contribute to the reduction of tiredness and fatigue [29], to the point that European legislation provides for the possibility for food products to claim to be a "source of [name of vitamin/s]" where this is the case, as listed in the Annex to Regulation (EC) No 1924/2006 [30], no data are available regarding the effect of pomegranate supplementation in prolonged or chronic fatigue, and this survey reports promising preliminary data on this topic. In fact, as far as hydrosoluble vitamin supplementation is concerned, there is a strong biological and physiological rationale that supports the role of B vitamins in the improvement of fatigue through cellular energy production, which, in turn, leads to beneficial effects, especially for muscle tissue and the brain, which are the most energy-demanding organs in the body. In a recent review of the literature, Tardy et al. showed that supplementation with B vitamins results in health benefits in the areas of mental and physical fatigue [6]. In particular, the authors report that a large body of evidence shows that an inadequate intake of hydrosoluble vitamins is a frequent issue worldwide, albeit with variations according to age groups and country, and inadequacies in $B$ vitamins and vitamin $C$ increase the risk of non-specific clinical symptoms including weakness, fatigue, loss of appetite, and apathy. The supplementation of hydrosoluble vitamins can improve fatigue due to their role in a variety of basic metabolic pathways that support energy-production systems, oxygen transport, and protection from oxidative stress. Moreover, thiamine, pantothenic acid, folate, and vitamin C play a role in the maintenance of brain structure, enabling intercellular connections, and in the synthesis of neurotransmitters, leading to an improvement in cognitive and psychological function.

As far as pomegranate is concerned, due to the healthy properties of pomegranate juice, it has been awarded the title of "super food" [31]. Although most pomegranate products studied for their healthy properties are derived from the edible part of the fruit (i.e., seeds and arils), the peel is rich in many health-promoting compounds (antioxidants and anti-inflammatory and immunomodulatory agents), which are often discarded as waste [32]. The extract used as an ingredient of this food supplement is obtained from the whole fruit and thus contains the whole phytocomplex. It was found to be especially rich in ellagitannins, to which many healthy properties are ascribed.

Although, to the best of our knowledge, no data are available on pomegranate supplementation and prolonged or chronic fatigue, recent studies performed on a wide range of athletes and physically active subjects showed that pomegranate juice and extracts improve whole body strength, feeling of vitality, and sport performance during intensive exercise, through an increase in vessel diameter and consequently in blood flow and $\mathrm{O}_{2}$ delivery to muscular requirements [33-35]. In addition, pomegranate supplementation has the potential to support recovery from exercise and relieve acute and delayed muscle fatigue, through the attenuation of oxidative stress and inflammation via the reduction of free radical production, lipid peroxidation, and inhibition of cellular inflammation transcripts (i.e., TNF-alpha, COX-2, and NF-kB) [17].

The well-known anti-inflammatory activity of pomegranate could be one of the mechanisms of action through which this fruit contributes to the alleviation of fatigue. Several studies showed that fatigue is associated with inflammation [36,37]. In a review of the literature, Lee at al. reported that subjects with fatigue have higher levels of proinflam- 
matory cytokines (i.e., interleukin- 1 and -6 and tumor necrosis factor alpha), supporting the hypothesis that anti-inflammatory treatments could help in reducing inflammation and somatic and phycological symptoms [15,38]. In 2019, Mastrogiovanni et al. showed that the extract obtained from pomegranate peel exerts strong anti-inflammatory activity both in vitro on Caco-2 cells stimulated by TNF-alpha, and ex vivo, using porcine colonic tissue explants stimulated with lipopolysaccharide, by inducing the reduction of the proinflammatory cytokine expression [39] Moreover, pomegranate juice and extracts were active in decreasing levels of pro-inflammatory cytokines in clinical trials involving patients with inflammatory diseases (i.e., hemodialysis patients, overweight and obese individuals, type 2 diabetes) [40-42]. Thus, further studies are needed to confirm these results, both in vitro with other cell model systems and in subjects with chronic inflammation as a risk factor for developing prolonged or chronic fatigue.

Another mechanism of action that could justify the positive results of the intake of pomegranate extract obtained against SF could be its ability to modify gut microbiota, as shown by recent studies. The association between gut microbiome and fatigue has been shown in many pathological conditions such as cancer patients, hematopoietic stem cell transplantation survivors, and multiple sclerosis patients, including myalgic encephalomyelitis/chronic fatigue syndrome patients [43]. In particular, subjects affected by chronic fatigue have low levels of bifidobacteria [44] and a significant increase in lactic acid produced by Enterococcus and Streptococcus in fecal samples [45]. Although no studies have considered the anti-fatigue activity of pomegranate and its effect on the gut microbiota composition, in 2020, Lu et al. showed that a pomegranate extract obtained from peel reshapes the composition of the gut microbiota, increasing eubiotic bacteria such as Lactobacillaceae, likely through polyphenolic components that are excreted unmodified into the intestinal lumen by bile and are then concentrated into the colon, where they are metabolized by gut colonic bacteria into low molecular weight substances such as urolithins, which modulate the gut microbiota and exert systemic anti-inflammatory activity [32].

\section{Conclusions}

In conclusion, this survey of consumers of dietary supplements aimed at alleviating fatigue provides some promising data on the effects on prolonged fatigue and the tolerability of a food supplement based on the combination of chemically characterized pomegranate extract, B vitamins, and vitamin C in healthy consumers for one month of intake. These preliminary results must be confirmed in a randomized double blind, placebo controlled clinical trial, in which the effects of the food supplement on fatigue and quality of life are not only assessed through questionnaires, but the expression of pro-inflammatory cytokines and the composition of gut microbiota are also evaluated.

Supplementary Materials: The following supporting information can be downloaded at: https: / / www.mdpi.com/article/10.3390/pr10020208/s1, Table S1: Compounds identified in pomegranate dry extract (PunicaPLUS ${ }^{\circledR}$ ) according to their retention time, area of chromatographic peak (arbitrarial unit) and area percentage (\%).

Author Contributions: Conceptualization, A.D.M., C.R. and M.D.; methodology, C.E., C.S., L.F.D.L., M.A.D.P. and F.M.; software, R.S.; formal analysis, E.S. and P.C.; writing-original draft preparation, R.S., L.F.D.L. and A.D.M., writing-review and editing, A.D.M., A.B. and M.D. All authors have read and agreed to the published version of the manuscript.

Funding: This research received no external funding.

Acknowledgments: The authors wish to express their gratitude to the pharmacists involved in this survey (Farmacia De Pasquale Giuseppe, Monte di Procida Naples, Italy). Moreover, we thank Eris Scott-Perring for providing the English revision. 
Conflicts of Interest: C.R. is an employee of ESSERRE srl. None of the academic researchers listed as co-authors served as consultant for ESSERRE srl or received any personal compensation from ESSERRE srl.

\section{References}

1. Fukuda, K.; Dobbins, J.G.; Wilson, L.J.; Dunn, R.A.; Wilcox, K.; Smallwood, D. An epidemiologic study of fatigue with relevance for the chronic fatigue syndrome. J. Psychiatr. Res. 1997, 31, 19-29. [CrossRef]

2. Baek, Y.; Kim, H.; Mun, S.; Lee, S. Three-Component Herbal Tea Alleviates Prolonged Fatigue and Improves Sleep Quality: A Randomized Controlled Pilot Study. EXPLORE 2018, 14, 420-423. [CrossRef]

3. Zielinski, M.R.; Systrom, D.M.; Rose, N.R. Fatigue, Sleep, and Autoimmune and Related Disorders. Front. Immunol. 2019, 10, 1827. [CrossRef] [PubMed]

4. Jason, L.A.; Evans, M.; Brown, M.; Porter, N. What is Fatigue? Pathological and Nonpathological Fatigue. PMER 2010, 2, 327-331. [CrossRef]

5. Klimas, N.G.; Broderick, G.; Fletcher, M.A. Biomarkers for chronic fatigue. Brain Behav. Immun. 2012, 26, 1202-1210. [CrossRef] [PubMed]

6. Tardy, A.-L.; Pouteau, E.; Marquez, D.; Yilmaz, C.; Scholey, A. Vitamins and Minerals for Energy, Fatigue and Cognition: A Narrative Review of the Biochemical and Clinical Evidence. Nutrients 2020, 12, 228. [CrossRef] [PubMed]

7. Portero, P.; Gomez-Merino, D. Stanchezza e Motilità. In EMC-Medicina Riabilitativa; Elsevier: Amsterdam, The Netherlands, 2013; Volume 20, pp. 1-12. [CrossRef]

8. Yancey, J.R.; Thomas, S.M. Chronic fatigue syndrome: Diagnosis and treatment. Am. Fam. Physician 2012, 86, 741-746. [PubMed]

9. Bucher, E.; Sandbakk, O.; Donath, L.; Roth, R.; Zahner, L.; Faude, O. Exercise-induced trunk fatigue decreases double poling performance in well-trained cross-country skiers. Graefe's Arch. Clin. Exp. Ophthalmol. 2018, 118, 2077-2087. [CrossRef]

10. Lin, C.F.; Lee, W.C.; Chen, Y.A.; Hsue, B.J. Fatigue-Induced Changes in Movement Pattern and Muscle Activity During Ballet Releve on Demi-Pointe. J. Appl. Biomech. 2016, 32, 350-358. [CrossRef]

11. Le Mansec, Y.; Pageaux, B.; Nordez, A.; Dorel, S.; Jubeau, M. Mental fatigue alters the speed and the accuracy of the ball in table tennis. J. Sports Sci. 2017, 36, 2751-2759. [CrossRef] [PubMed]

12. Salva, M.A.Q.; Barbot, F.; Hartley, S.; Sauvagnac, R.; Vaugier, I.; Lofaso, F.; Philip, P. Sleep disorders, sleepiness, and near-miss accidents among long-distance highway drivers in the summertime. Sleep Med. 2014, 15, 23-26. [CrossRef]

13. Nourbakhsh, B.; Revirajan, N.; Morris, B.; Cordano, C.; Creasman, J.; Manguinao, M.; Krysko, K.; Rutatangwa, A.; Auvray, C.; Aljarallah, S.; et al. Safety and efficacy of amantadine, modafinil, and methylphenidate for fatigue in multiple sclerosis: A randomised, placebo-controlled, crossover, double-blind trial. Lancet Neurol. 2020, 20, 38-48. [CrossRef]

14. Werbach, M.R. Nutritional strategies for treating chronic fatigue syndrome. Altern. Med. Rev. 2000, 5, 93-108.

15. Haß, U.; Herpich, C.; Norman, K. Anti-Inflammatory Diets and Fatigue. Nutrients 2019, 11, 2315. [CrossRef] [PubMed]

16. Wang, P.; Zhang, Q.; Hou, H.; Liu, Z.; Wang, L.; Rasekhmagham, R.; Kord-Varkaneh, H.; Santos, H.O.; Yao, G. The effects of pomegranate supplementation on biomarkers of inflammation and endothelial dysfunction: A meta-analysis and systematic review. Complement. Ther. Med. 2020, 49, 102358. [CrossRef] [PubMed]

17. Ammar, A.; Bailey, S.; Chtourou, H.; Trabelsi, K.; Turki, M.; Hökelmann, A.; Souissi, N. Effects of pomegranate supplementation on exercise performance and post-exercise recovery in healthy adults: A systematic review. Br. J. Nutr. 2018, 120, 1201-1216. [CrossRef] [PubMed]

18. Urbaniak, A.; Skarpańska-Stejnborn, A. Effect of pomegranate fruit supplementation on performance and various markers in athletes and active subjects: A systematic review. Int. J. Vitam. Nutr. Res. 2021, 91, 547-561. [CrossRef] [PubMed]

19. Drent, M.; Lower, E.E.; De Vries, J. Sarcoidosis-associated fatigue. Eur. Respir. J. 2012, 40, 255-263. [CrossRef] [PubMed]

20. de Kleijn, W.P.; De Vries, J.; Wijnen, P.A.; Drent, M. Minimal (clinically) important differences for the Fatigue Assessment Scale in sarcoidosis. Respir. Med. 2011, 105, 1388-1395. [CrossRef] [PubMed]

21. De Vries, J.; Michielsen, H.; Van Heck, G.L.; Drent, M. Measuring fatigue in sarcoidosis: The Fatigue Assessment Scale (FAS). Br. J. Health Psychol. 2004, 9, 279-291. [CrossRef]

22. Krupp, L.B.; LaRocca, N.G.; Muir-Nash, J.; Steinberg, A.D. The Fatigue Severity Scale: Application to Patients With Multiple Sclerosis and Systemic Lupus Erythematosus. Arch. Neurol. 1989, 46, 1121-1123. [CrossRef]

23. Morgul, E.; Bener, A.; Atak, M.; Akyel, S.; Aktaş, S.; Bhugra, D.; Ventriglio, A.; Jordan, T.R. COVID-19 pandemic and psychological fatigue in Turkey. Int. J. Soc. Psychiatry 2020, 67, 128-135. [CrossRef] [PubMed]

24. Hjollund, N.H.; Andersen, J.H.; Bech, P. Assessment of fatigue in chronic disease: A bibliographic study of fatigue measurement scales. Health Qual. Life Outcomes 2007, 5, 12. [CrossRef] [PubMed]

25. Gladman, D.; Nash, P.; Goto, H.; Birt, J.A.; Lin, C.-Y.; Orbai, A.-M.; Kvien, T.K. Fatigue numeric rating scale validity, discrimination and responder definition in patients with psoriatic arthritis. RMD Open 2020, 6, e000928. [CrossRef]

26. Gandek, B.; Ware, J.E.; Aaronson, N.K.; Apolone, G.; Bjorner, J.B.; Brazier, J.E.; Bullinger, M.; Kaasa, S.; Leplege, A.; Prieto, L.; et al. Cross-Validation of Item Selection and Scoring for the SF-12 Health Survey in Nine Countries: Results from the IQOLA Project. International Quality of Life Assessment. J. Clin. Epidemiol. 1998, 51, 1171-1178. [CrossRef]

27. Ware, J.E.; Keller, S.D. SF-12: How to Score the SF-12 Physical and Mental Health Summary Scales, 2nd ed.; Health Institute, New England Medical Center: Boston, MA, USA, 1995. 
28. Moga, M.; Dimienescu, O.; Bălan, A.; Dima, L.; Toma, S.; Bîgiu, N.; Blidaru, A. Pharmacological and Therapeutic Properties of Punica granatum Phytochemicals: Possible Roles in Breast Cancer. Molecules 2021, 26, 1054. [CrossRef]

29. The European Commission. Commission Regulation (EU) No. 432/2012 Establishing a List of Permitted Health Claims Made on Foods, Other Than Those Referring to the Reduction of Disease Risk and to Children's Development and Health; Official Journal of European Union. 2012. Available online: https: / / eur-lex.europa.eu/LexUriServ/LexUriServ.do?uri=OJ:L:2012:136:0001:0040: en:PDF (accessed on 8 December 2021).

30. The European Commission. Regulation (EC) No. 1924/2006 of the European Parliament and of the Council on Nutrition and Health Claims Made on Foods; Official Journal of European Union. 2006. Available online: https://eur-lex.europa.eu/ LexUriServ/LexUriServ.do?uri=OJ:L:2006:404:0009:0025:En:PDF (accessed on 8 December 2021).

31. Fahmy, H.; Hegazi, N.; El-Shamy, S.; Farag, M.A. Pomegranate juice as a functional food: A comprehensive review of its polyphenols, therapeutic merits, and recent patents. Food Funct. 2020, 11, 5768-5781. [CrossRef]

32. Lu, X.-Y.; Han, B.; Deng, X.; Deng, S.-Y.; Zhang, Y.-Y.; Shen, P.-X.; Hui, T.; Chen, R.-H.; Li, X.; Zhang, Y. Pomegranate peel extract ameliorates the severity of experimental autoimmune encephalomyelitis via modulation of gut microbiota. Gut Microbes 2020, 12, 1857515. [CrossRef] [PubMed]

33. Trexler, E.T.; Smith-Ryan, A.E.; Melvin, M.N.; Roelofs, E.J.; Wingfield, H.L. Effects of pomegranate extract on blood flow and running time to exhaustion. Appl. Physiol. Nutr. Metab. 2014, 39, 1038-1042. [CrossRef]

34. Torregrosa-García, A.; Ávila-Gandía, V.; Luque-Rubia, A.J.; Abellán-Ruiz, M.S.; Querol-Calderón, M.; López-Román, F.J. Pomegranate Extract Improves Maximal Performance of Trained Cyclists after an Exhausting Endurance Trial: A Randomised Controlled Trial. Nutrients 2019, 11, 721. [CrossRef]

35. Roelofs, E.J.; Smith-Ryan, A.E.; Trexler, E.T.; Hirsch, K.R.; Mock, M.G. Effects of pomegranate extract on blood flow and vessel diameter after high-intensity exercise in young, healthy adults. Eur. J. Sport Sci. 2016, 17, 317-325. [CrossRef] [PubMed]

36. Louati, K.; Berenbaum, F. Fatigue in chronic inflammation-A link to pain pathways. Arthritis Res. Ther. 2015, 17, 254. [CrossRef]

37. Maes, M.; Twisk, F.; Kubera, M.; Ringel, K. Evidence for inflammation and activation of cell-mediated immunity in Myalgic Encephalomyelitis/Chronic Fatigue Syndrome (ME/CFS): Increased interleukin-1, tumor necrosis factor- $\alpha$, PMN-elastase, lysozyme and neopterin. J. Affect. Disord. 2012, 136, 933-939. [CrossRef]

38. Lee, C.-H.; Giuliani, F. The Role of Inflammation in Depression and Fatigue. Front. Immunol. 2019, 10, 1696. [CrossRef] [PubMed]

39. Mastrogiovanni, F.; Mukhopadhya, A.; Lacetera, N.; Ryan, M.T.; Romani, A.; Bernini, R.; Sweeney, T. Anti-Inflammatory Effects of Pomegranate Peel Extracts on In Vitro Human Intestinal Caco-2 Cells and Ex Vivo Porcine Colonic Tissue Explants. Nutrients 2019, 11, 548. [CrossRef]

40. Boldaji, R.B.; Akhlaghi, M.; Sagheb, M.M.; Esmaeilinezhad, Z. Pomegranate juice improves cardiometabolic risk factors, biomarkers of oxidative stress and inflammation in hemodialysis patients: A randomized crossover trial. J. Sci. Food Agric. 2019, 100, 846-854. [CrossRef] [PubMed]

41. Shishehbor, F.; Shahi, M.M.; Zarei, M.; Saki, A.; Zakerkish, M.; Shirani, F.; Zare, M. Effects of Concentrated Pomegranate Juice on Subclinical Inflammation and Cardiometabolic Risk Factors for Type 2 Diabetes: A Quasi-Experimental Study. Int. J. Endocrinol. Metab. 2016, 14, e33835. [CrossRef]

42. Hosseini, B.; Saedisomeolia, A.; Wood, L.G.; Yaseri, M.; Tavasoli, S. Effects of pomegranate extract supplementation on inflammation in overweight and obese individuals: A randomized controlled clinical trial. Complement. Ther. Clin. Pract. 2016, 22, 44-50. [CrossRef]

43. Frémont, M.; Coomans, D.; Massart, S.; De Meirleir, K. High-throughput 16S rRNA gene sequencing reveals alterations of intestinal microbiota in myalgic encephalomyelitis/chronic fatigue syndrome patients. Anaerobe 2013, 22, 50-56. [CrossRef] [PubMed]

44. Logan, A.C.; Rao, A.V.; Irani, D. Chronic fatigue syndrome: Lactic acid bacteria may be of therapeutic value. Med. Hypotheses 2003, 60, 915-923. [CrossRef]

45. Sheedy, J.R.; Wettenhall, R.E.H.; Scanlon, D.; Gooley, P.R.; Lewis, D.P.; McGregor, N.; Stapleton, D.I.; Butt, H.L.; De Meirleir, K.L. Increased d-lactic Acid intestinal bacteria in patients with chronic fatigue syndrome. In Vivo 2009, 23, 621-628. [PubMed] 